\title{
Sub-micron lithography using InGaN micro-LEDs: mask-free fabrication of high-fill factor LED arrays
}

\author{
B. Guilhabert, D. Massoubre*, E. Richardson, J. J. D. McKendry, G. Valentine, R. K. Henderson, \\ I.M. Watson, E. Gu and M. D. Dawson, Fellow, IEEE
}

\begin{abstract}
The fabrication of gallium-nitride based (GaN) light emitting diode (LED) arrays by a direct writing technique, itself using micron-sized LEDs (micro-LEDs), is reported. CMOSdriven ultraviolet GaN-based micro-LED arrays were used to pattern photoresist layers with feature sizes as small as $500 \mathrm{~nm}$. Chequerboard-type square LED array devices were then fabricated using such photoresist patterns based on either single pixel or multi-pixel direct writing, and implemented as part of a completely mask-less process flow. These exemplar arrays comprised either $450 \mathrm{~nm}$-emitting $199 \times 199 \mu \mathrm{m}^{2}$ pixels on a $200 \mu \mathrm{m}$ pitch or $520 \mathrm{~nm}$-emitting $21 \times 18 \mu^{2}$ pixels on a $23 \mu \mathrm{m}$ pitch. Fillfactors of $99 \%$ and $71.5 \%$ were achieved with optical output power densities per pixel of $5 \mathrm{~W} / \mathrm{cm}^{2}$ and $20 \mathrm{~W} / \mathrm{cm}^{2}$ at $90 \mathrm{~mA}$ and 6mA dc injected currents, respectively.
\end{abstract}

Index Terms-Gallium nitride, micro light-emitting diodes (micro-LEDs), nanolithography, semiconductor device manufacture

\section{INTRODUCTION}

Standard manufacture of semiconductor devices requires multiple fabrication steps which involve patterning of photoresist (PR) by ultraviolet (UV) light exposure through a series of customized quartz-based photomasks. Consequently, each change in design requires the production of one or more new and expensive photomasks. As an alternative, maskless fabrication approaches have attracted much attention as they offer flexibility and significant reduction of fabrication cost. Several maskless methods have been developed including laser direct writing, 2-photon writing, interference lithography and inkjet printing, and these techniques have already been used for the fabrication of optoelectronic devices. ${ }^{[1-3]}$ III-nitride semiconductor technology can already provide efficient LEDs with peak emission wavelengths around $365 \mathrm{~nm}$ and $405 \mathrm{~nm}$, corresponding respectively to the i-line and h-line emissions from mercury discharge lamps used in mature photolithography. However, related III-nitride LEDs are also being developed offering emission into the deep UV, compatible with the majority of photo-acid generators and more advanced optical lithography. ${ }^{[4]}$ In addition, III-nitride LEDs offer many advantages compared to mercury lamps,

Manuscript received August 17, 2012. This work was supported by EPSRC under the grants EP/D078555/1 and EP/F05999X/1. B. Guilhabert and D. Massoubre contributed equally to this work.

B. Guilhabert, D. Massoubre, E. Richardson, J. J. D. McKendry, I. M. Watson, E. Gu and M. D. Dawson are with the Institute of Photonics, University of Strathclyde, 106 Rottenrow, Glasgow G4 0NW, UK, e-mail: benoit.guilhabert@strath.ac.uk; david.massoubre@strath.ac.uk

G. Valentine was with the Institute of Photonics, Glasgow, UK. He is now with mLED ltd, Glasgow G20 0SP, UK (http://www.mled-ltd.com/)

R. K. Henderson is with the Joint Research Institute for Integrated Systems, Institute for Micro and Nano Systems, School of Engineering, The University of Edinburgh, Edinburgh EH93JL, U.K. including compactness, low power consumption and no content of toxic material. Furthermore, the output power of these LEDs and their emission mode (pulsed and dc) can be easily changed via an integrated electronic driver circuit. Several proof-of-concept demonstrations of micro-patterning by LED direct writing have already been made using either conventional broad-area devices or micro-LEDs (we consider an LED as "micro" when one of its dimensions is below $100 \mu \mathrm{m}) .{ }^{[5-7]}$ Feature sizes as small as $20 \mu \mathrm{m}$ were obtained by using proximity exposure with micro-LEDs, while similar feature sizes have also been obtained using a broad-area LED source coupled to a microscope objective. ${ }^{[5,6]}$ The use of micro-LEDs brings the primary advantages of offering a large density of emitters on a small-scale chip, and a higher power density per pixel than broad-area LEDs. ${ }^{[8]}$

We report here on the use of $8 \times 8$ micro-LED arrays with pixel sizes as small as $14 \mu \mathrm{m}$-diameter in an imaging optical setup (similar to the setup in ref. [10] but with a 10:1 demagnification) to pattern PR with features down to $500 \mathrm{~nm}$ width in order to process GaN-based LED heterostructures. $^{[9,10]}$ First, a single pixel was used to pattern a sacrificial PR mask for a "chequerboard-type" array with individually addressable LEDs emitting at 450nm. ${ }^{[11]}$ The chequerboard device was designed with a targeted $1 \mu \mathrm{m}$ gap between adjacent pixels, resulting in a $99 \%$ filling factor arrays in a suitable configuration for subsequent flip-chip bonding to custom complementary metal-oxide-semiconductor (CMOS). ${ }^{[9,13]}$ Typical measured optical output powers here were $2 \mathrm{~mW}\left(5 \mathrm{~W} / \mathrm{cm}^{2}\right)$ per pixel at a driving current of $90 \mathrm{~mA}$. Parallel direct writing is then implemented using 2 micropixels each of $24 \mu \mathrm{m}$ diameter to create a $32 \times 32$ chequerboard design emitting at $520 \mathrm{~nm}$. This had $21 \times 18 \mu \mathrm{m}^{2}$ pixels on a $23 \mu \mathrm{m}$ pitch, each delivering $77 \mu \mathrm{W}\left(20 \mathrm{~W} / \mathrm{cm}^{2}\right)$ at $6 \mathrm{~mA}$ injection current. These arrays were fabricated in a suitable configuration for applications including lab-on-chip sensors, micro-displays, time-resolved spectroscopy and optoelectronic tweezing, ${ }^{[12,13]}$ and provide demanding demonstrations of the capabilities of micro-LED direct writing in the rapid and accurate fabrication of active optoelectronic devices.

\section{MICRO-LED MASK-FREE LITHOGRAPHY}

This work used micro-LED arrays emitting at a wavelength of $370 \mathrm{~nm}$, flip-chip bonded onto a CMOS silicon backplane. ${ }^{[9,13]}$ The micro-LED device is an $8 \times 8$ array of micro-disk pixels on a $200 \mu \mathrm{m}$ pitch with diameters progressing from $84 \mu \mathrm{m}$ to $14 \mu \mathrm{m}$ in $10 \mu \mathrm{m}$ steps. The pixels are arranged in rows with fixed pixel diameters. All the pixels share a common negative electrode (n-contact) and are individually addressed through their respective positive contact (p-contact). Each pixel is provided with a $92 \times 92 \mu \mathrm{m}^{2}$ separate bonding pad, connected to the pixel with a metal track 
to complete the positive connection (inset Fig. 1.). This method of off-pixel bonding facilitates contacting of smallsized pixels to enable the highest direct writing resolution. CMOS driving offers the capability of individual $\mathrm{dc}$ and pulsed operation of the micro-LEDs down to few hundreds of picoseconds through a computer-controlled interface as well as projection of programmable patterns. ${ }^{[9]}$ The forward bias voltage versus current of representative CMOS-bonded $14 \mu \mathrm{m}$ and $24 \mu \mathrm{m}$-diameter pixels is shown in Fig. 1. Turn-on voltages estimated with the tangent method are about $6 \mathrm{~V}$ and $5.5 \mathrm{~V}$ respectively, and currents of $20 \mathrm{~mA}$ are reached for bias voltages of $7.6 \mathrm{~V}$ and $7.1 \mathrm{~V}$, respectively. The CMOS chip design allows a maximum forward bias of 8V. Typical optical output powers were measured with a large-area $\mathrm{Si}$ photodetector placed in near contact above the device, so as to collect all of the front-emitted optical power. Typical optical output powers as a function of injected current are plotted in Fig. 1. At $20 \mathrm{~mA}$, optical power of $210 \mu \mathrm{W}(14 \mu \mathrm{m}$ device) and $275 \mu \mathrm{W}(24 \mu \mathrm{m}$ device $)$ were measured.

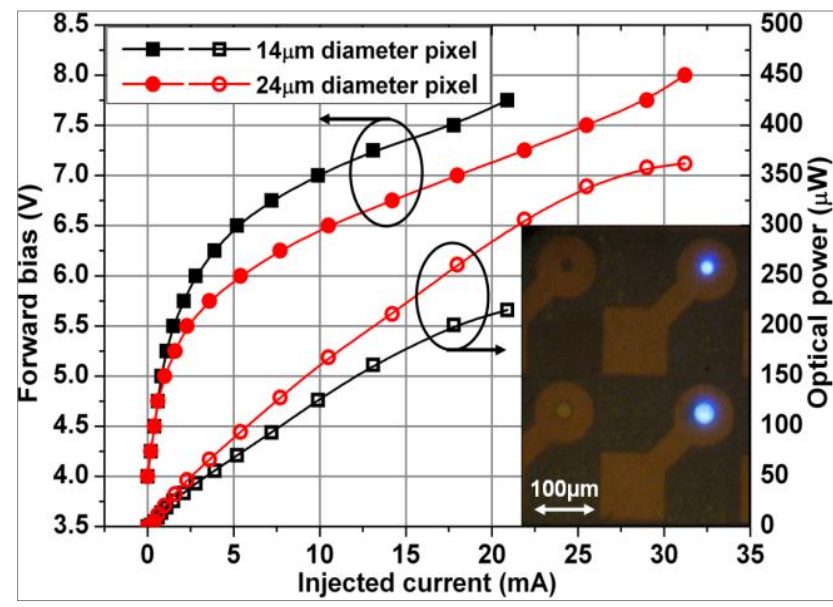

Fig. 1. : Voltage and optical output power versus injected current of two representative pixels of $14 \mu \mathrm{m}$ and $24 \mu \mathrm{m}$ in diameter emitting at $370 \mathrm{~nm}$. Inset, an optical micrograph of representative pixels of $14 \mu \mathrm{m}$ and $24 \mu \mathrm{m}$ diameters individually addressed from the $8 \times 8$ micro-LED arrays.

In the following direct writing experiments, micro-LEDs are imaged using an optical setup as in [10], using a $4 \mathrm{x}$ and 40x microscope objectives for collection and projection, respectively, and demagnifying the pixels by a factor 10 . The sample covered with PR is placed on an X-Y translation stage and positioned at the focus using the high-resolution $\mathrm{z}$-stage supporting the $40 \mathrm{x}$ projection microscope objective. ${ }^{[10]}$ The writing process itself is entirely automated through a computer interface. For the first demonstration, single micro-LEDs were used to evaluate the writing performance of the setup. The CMOS was configured to drive in dc mode at a voltage of $5 \mathrm{~V}$ and the power densities were measured at focus in this configuration for all the pixels of diameters $14 \mu \mathrm{m}$ and $24 \mu \mathrm{m}$ (Fig. 2(a)). Average optical power densities of $1.7 \mathrm{~W} / \mathrm{cm}^{2}$ and $1.2 \mathrm{~W} / \mathrm{cm}^{2}$ with variances of $0.3 \mathrm{~W} / \mathrm{cm}^{2}$ and $0.2 \mathrm{~W} / \mathrm{cm}^{2}$ are calculated from these sets of results. The velocities of the $\mathrm{X}-\mathrm{Y}$ stages are controlled to deliver the appropriate exposure dose and to adjust the feature size written into the PR. Typical writing speeds range from $20 \mu \mathrm{m} / \mathrm{s}$ to $140 \mu \mathrm{m} / \mathrm{s}$ leading to average exposure doses at focus of $280 \mathrm{~mJ} / \mathrm{cm}^{2}$ down to $40 \mathrm{~mJ} / \mathrm{cm}^{2}$ for the $14 \mu \mathrm{m}$-diameter pixel and from $360 \mathrm{~mJ} / \mathrm{cm}^{2}$ to $51 \mathrm{~mJ} / \mathrm{cm}^{2}$ for the $24 \mu \mathrm{m}$-diameter. ${ }^{[10]}$ Feature sizes written at different velocities by both pixels were investigated by atomic force microscopy (AFM) over an area of $5 \times 5 \mu \mathrm{m}^{2}$ of the patterned region. Trenches were written in resist S1805 (600nm thick) which requires an exposure dose at $370 \mathrm{~nm}$ of $40 \mathrm{~mJ} / \mathrm{cm}^{2}$ (value from manufacturer's datasheet). Fig. 2 (b) summarizes the measured trench bottom widths for these writing experiments ranging from $9 \mu \mathrm{m}$ down to $2 \mu \mathrm{m}$ and $6 \mu \mathrm{m}$ down to $0.5 \mu \mathrm{m}$ for the $24 \mu \mathrm{m}$ and $14 \mu \mathrm{m}$-diameter pixels, respectively. The inset of Fig. 2 shows a $500 \mathrm{~nm}$ base-width trench realized with the $14 \mu \mathrm{m}$-diameter pixel at a writing speed of $140 \mu \mathrm{m} / \mathrm{s}$. The profile shows a significant nonverticality of the trench sidewalls, resulting from the intrinsic exposure profile of the PR film, but not posing limitations for the microfabrication applications envisaged.
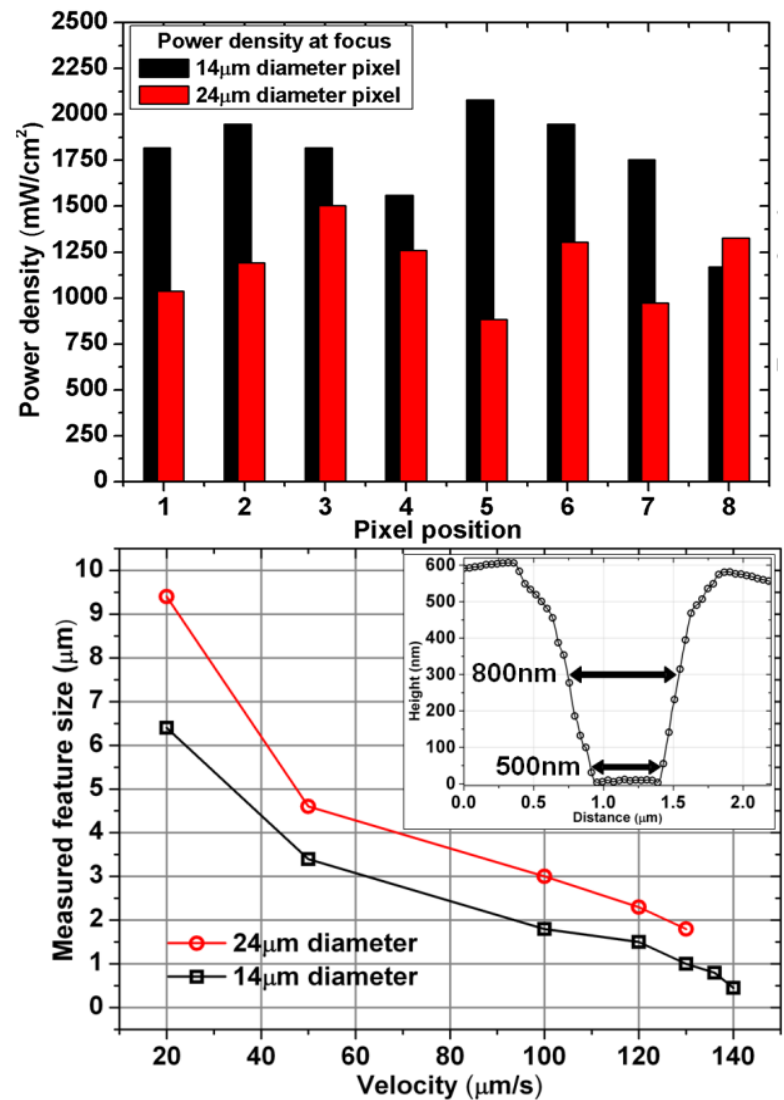

Fig. 2. : a) Optical power densities evaluated at focus for pixels diameter of $14 \mu \mathrm{m}$ and $24 \mu \mathrm{m}$ (1.4 and $2.4 \mu \mathrm{m}$ diameter at focus, respectively) for a drive voltage of 5V. b) S1805 PR feature sizes (trench bottom) exposed by representative pixels of each diameter upon increased stages velocity. Inset: AFM scan nrofile of a $\mathrm{S} 1805$ trench written at $1401 \mathrm{~m} \mathrm{~m}^{-1}$.

\section{DEVICE FABRICATION AND CHARACTERIZATION}

First, a chequerboard-type LED design with an 8x8 array of $200 \mu$ m-pitch, $199 \times 199 \mu \mathrm{m}^{2}$ LEDs was chosen as a demonstrator device, as each pixel can be easily individually wire bonded. Also it is directly compatible with the CMOSbackplane technology which has been developed to bond and drive our custom LED array devices. ${ }^{[9]}$ The chequerboard GaN-based LED array was fabricated from a commercial $p-i-n$ 
LED wafer grown on c-plane sapphire, with a peak emission wavelength of $450 \mathrm{~nm}$. After a de-oxidation step in $\mathrm{HCl}$, the deposition of a bilayer of Ni/Au $(10 \mathrm{~nm} / 20 \mathrm{~nm})$ was performed by electron beam evaporation, followed by rapid thermal annealing at $500^{\circ} \mathrm{C}$ for $120 \mathrm{~s}$ in purified air ambient to form semi-transparent ohmic contacts to the p-doped $\mathrm{GaN}$ layer. Next, a $50 \mathrm{~nm} / 200 \mathrm{~nm}$ Ti/Au bilayer (used both as high reflectance mirror and high conductance electrode) was deposited by sputtering, followed by a plasma-enhanced chemical vapour deposition of a $500 \mathrm{~nm}$-thick $\mathrm{SiO}_{2}$ layer to be used as a hard mask for subsequent etching. A $600 \mathrm{~nm}$-thick PR film was spin-coated and soft-baked according to the vendor's datasheet in preparation for the micro-LED pattern writing. The maskless patterning to define the LED mesa was performed at a linear translation speed of $140 \mu \mathrm{m} / \mathrm{s}$ using a single $14 \mu \mathrm{m}$ pixel. The velocity was then reduced to $10 \mu \mathrm{m} / \mathrm{s}$ in order to write a large frame around the emission area for access to the n-doped GaN (see Fig. 3(a)). The PR was then developed using a standard solution providing minimum features of about $560 \mathrm{~nm}$ in width on average forming the $8 \times 8$ array and a surrounding frame of about $35 \mu \mathrm{m}$ width around the array. This pattern was then transferred to the $\mathrm{SiO}_{2}$ layer by reactive ion etching and a multi-step process combining wet and inductively coupled plasma etching was used to etch the metal stack and the GaN-based layers down to the n-GaN layer, resulting in an $8 \times 8 \mathrm{n}$-shared mesa array. Finally the residual $\mathrm{SiO}_{2}$ layer was stripped off the sample by wet etching. An optical micrograph of the chequerboard device's p-contact side after processing is shown in Fig. 3(a), left. Each trench is well defined with an average width close to the targeted value
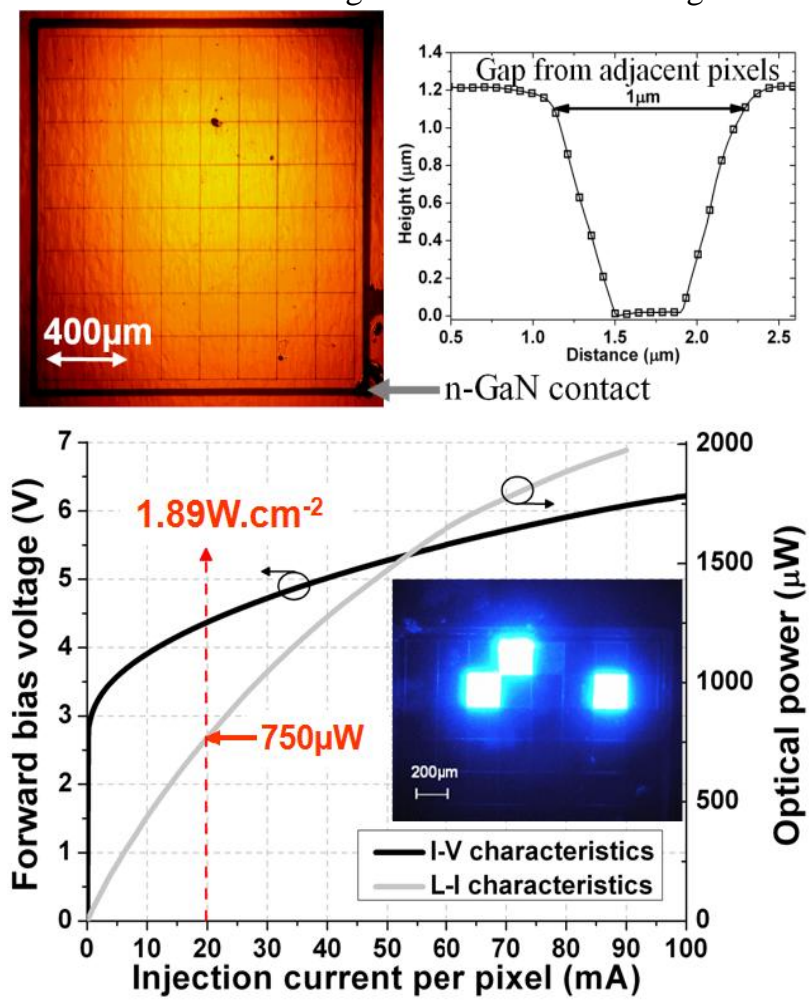

Fig. 3. : a) Optical micrograph of the entire 450-nm emitting 8x8 array (left) and AFM scan profile of a representative gap between adjacent pixels of the array (right). b) I-V and L-I characteristics of a typical pixel of the $8 \times 8$ array with, inset, an optical micrograph of several pixels individually addressed. of $1 \mu \mathrm{m}$ (Fig .3(a), right). The final gaps between pixels are larger than the PR feature defined by the mask-less lithography $(560 \mathrm{~nm})$ owing to the finite isotropic component of the various dry etch steps acting on the sidewalls.

An inkjet printing step of silver $(\mathrm{Ag})$ nanoparticles defined metal tracks to connect the shared $\mathrm{n}-\mathrm{GaN}$ in order to avoid a metal lift-off step and thus to demonstrate a full maskless fabrication process. The Ag nanoparticles (Silverjet DGP, $40 \% \mathrm{w} / \mathrm{w}$ ) were printed with a Dimatix DMP-2800 system with a $35 \mu \mathrm{m}$ drop separation to give suitable droplet coalescence on the sample to generate continuous metal tracks. ${ }^{[14]}$ Heating at $200^{\circ} \mathrm{C}$ for 2 hours evaporated the residual solvent from the metal tracks and improved the tracks' conductivity through sintering. The resistivity of the printed tracks was measured using a 2-point probe method knowing the cross-section (measured by profilometry) and the length between probes (measured on a test sample with $\mathrm{SiO}_{2}$ as substrate). After sintering, the resistivity of the $\mathrm{Ag}$ tracks thereby obtained is $15.4 \mu \Omega$.cm (versus $1.59 \mu \Omega$.cm for bulk $\mathrm{Ag}$ ). Each pixel was finally individually wire bonded to a printed circuit board for characterization purposes. The inset of Fig. 3(b) shows an optical micrograph of the chequerboardLED array with representative pixels turned on, demonstrating the individually-addressable capabilities of the device. The electrical and optical performance of the array was assessed. Typical injection current versus forward bias voltage (I-V) and optical output power versus injection current (L-I) characteristics of a representative pixel are shown in Fig. 3(b). The directed optical output was measured from the back side of the device (through the transparent sapphire substrate) using a power meter and a calibrated $\mathrm{Si}$ photodetector placed in close proximity. The device shows good electrical and optical performance with a maximum output optical power of $2 \mathrm{~mW}$ $\left(5 \mathrm{~W} / \mathrm{cm}^{2}\right)$ at an injected current of $90 \mathrm{~mA}\left(750 \mu \mathrm{W}-2 \mathrm{~W} / \mathrm{cm}^{2}\right.$ at $20 \mathrm{~mA}$ injected current). A typical voltage of $4.3 \mathrm{~V}$ at $20 \mathrm{~mA}$ is measured which is somewhat higher than a typical GaN-based LED (usually around $3 \mathrm{~V}$ ). This is likely due to the lower conductivity of the nanoparticle $\mathrm{Ag}$ ink and the higher potential barrier at the $\mathrm{Ag} / \mathrm{n}-\mathrm{GaN}$ interface compared with a more standard n-metal contact such as Ti/Au, but is illustrative of the potential for a fully maskless LED fabrication process flow.

The parallel writing capability of our setup was then demonstrated with 2 adjacent $24 \mu \mathrm{m}$-diameter pixels (namely pixels 7 and 8 from Fig. 2(a)) driven at the same forward bias voltage, $7.5 \mathrm{~V}$ (25.5mA typical dc injected current). The pixels were both placed within the field of view of the collection microscope objective so that their emission is collected altogether. In this configuration and driven individually, each pixel delivers a different optical power at focus of $0.163 \mu \mathrm{W}$ $\left(3.6 \mathrm{~W} / \mathrm{cm}^{2}\right)$ and $0.17 \mu \mathrm{W}\left(3.75 \mathrm{~W} / \mathrm{cm}^{2}\right)$, respectively, due to variation in pixel-to-pixel performances as shown in Fig. 2(a). However, due to the characteristics of the CMOS design, the current flowing through the chip when several LEDs are driven simultaneously induces a voltage drop at the LED electrodes due to the ground bounce effect. ${ }^{[15]}$ Consequently, when driven 
simultaneously, the optical power projected is not the sum of the individual optical powers, instead a total optical power at focus of $0.131 \mu \mathrm{W}\left(2.9 \mathrm{~W} / \mathrm{cm}^{2}\right)$ is estimated per driven pixel. The chequerboard-design was again chosen to illustrate the lithographic capability in this case for high density micro-LED arrays emitting at $520 \mathrm{~nm}$. An array of $32 \times 32$ elements with a $23-\mu \mathrm{m}$ pitch was thus coded for a 2 pixel writing experiment. In the vertical direction (direction according to inset of Fig. 4.) each trench is exposed using a single pixel while, in the horizontal direction, both pixels are used consecutively. The writing speed was fixed to $100 \mu \mathrm{m} / \mathrm{s}$ in vertical giving a typical exposure dose of $69 \mathrm{~mJ} / \mathrm{cm}^{2}$, and $200 \mu \mathrm{m} / \mathrm{s}$ in the horizontal direction to take into account the overlapping exposure path from the two pixels. After PR patterning, the same etching process was applied as described previously resulting in an array of individually-addressable rectangular pixels. In this case the resulting fill-factor is reduced to $71.5 \%$ with $21 \mathrm{x} 18 \mu \mathrm{m}^{2}$ pixels as shown in the optical micrograph inset of Fig. 4. Probes were used here to electrically and optically characterize the device. Fig. 4 summarizes the typical I-V and L-I curves for a pixel of the array. The pixel delivers an optical power of $77 \mu \mathrm{W}$ at an injection current of $6 \mathrm{~mA}$, giving an optical power density of $20 \mathrm{~W} / \mathrm{cm}^{2}$ with current density of $1.6 \mathrm{kA} / \mathrm{cm}^{2}$.

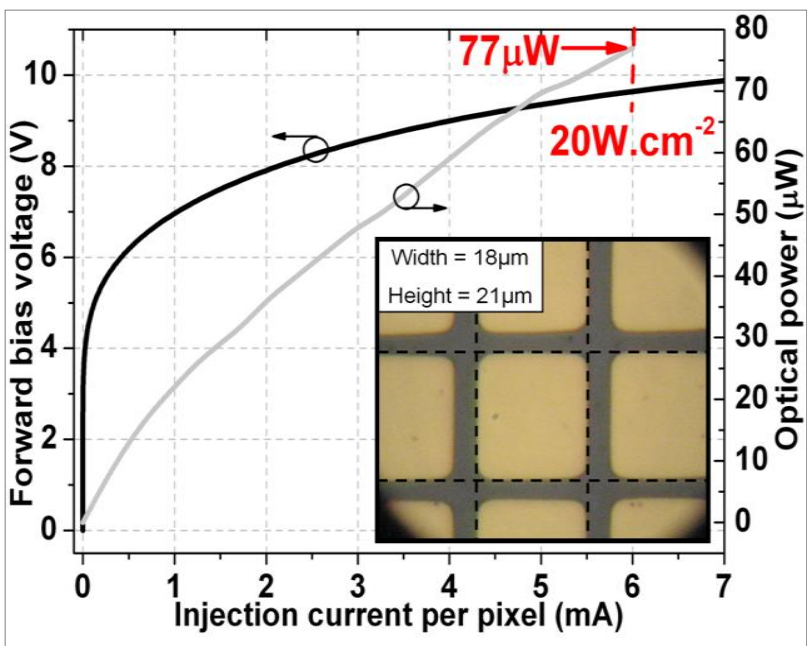

Fig. 4. : I-V and L-I characteristics of a typical pixel of the 520-nm emitting $32 \times 32$ elements array with, inset, an optical micrograph centered on a pixel from the array.

\section{CONCLUSION}

A custom-made 370-nm emitting micro-LED array bonded on CMOS backplane was used as a maskless photolithography tool to fabricate complex and tailored optoelectronic devices through the use of an optical demagnifying setup and computer control. This direct writing technique was first used to pattern PR layers giving features as narrow as $500 \mathrm{~nm}$ at $140 \mu \mathrm{m} / \mathrm{s}$ writing velocities. In combination with wet and dry etching and inkjet printing, custom designed 450nm emitting, 99\% fillfactor, $8 \times 8$ broad-LED array and 520nm-emitting $32 \times 32$ micro-LED array were fabricated by single and two-pixels parallel writing respectively. Typical optical output powers emitted by a single element were measured to be up to $5 \mathrm{~W} / \mathrm{cm}^{2}$ and $20 \mathrm{~mW} / \mathrm{cm}^{2}$, respectively, at injected current of $90 \mathrm{~mA}$ and $6 \mathrm{~mA}$. These results demonstrate the advantages of micro-LED maskless lithography, including re-configurable written patterns with sub-micron feature sizes and multi-beam parallel writing and implementation as part of a mask-less process flow, to address the easy fabrication of complex optoelectronic and photonic devices such as, but not limited to, GaN-based LED arrays.

\section{REFERENCES}

[1] C. Rensch, S. Hell, M. Schickfus and S. Hunklinger, "Laser scanner for direct writing lithography", Appl. Opt., vol. 28, pp. 3754-3758, 1989

[2] J. Serbin, A. Egbert, A. Ostendorf, B. N. Chichkov, R. Houbertz, G Domann, J. Schulz, C. Cronauer, L. Fröhlich and M. Popall, “ Femtosecond laser-induced two-photon polymerization of inorganic organic hybrid materials for applications in photonics", Opt. Lett., vol. 28, pp. 301-303, 2003

[3] I. Byun and J. Kim, "Cost-effective laser interference lithography using a $405 \mathrm{~nm}$ AlInGaN semiconductor laser", J. Micromech. Microeng., vol. 20, pp. 055024, 2010

[4] M. Asif-Kahn, K. Balakrishnan and T. Katona, "Ultraviolet lightemitting diodes based on group three nitrides", Nature Photonics, vol. 2, pp. 77-84, 2008

[5] C.-W. Jeon, E. Gu and M. D. Dawson, "Mask-free photolithographic exposure using a matrix-addressable micropixellated AlInGaN ultraviolet light-emitting diode", Appl. Phys. Lett., vol. 86, pp. 221105, 2005

[6] R. M. Guijt and M. C. Breadmore, "Maskless photolithography using UV LEDs", Lab-on-a-Chip, vol. 8, pp. 1402-1404, 2008

[7] S. Suzuk and Y. Matsumoto, "Lithography with UV LED array for curved surface structure", Microsyst. Technol., vol. 14, pp. 1291-1297, 2008

[8] H. X. Zhang, D. Massoubre, J. J. D. McKendry, Z. Gong, B. Guilhabert, C. Griffin, E. Gu, P. E. Jessop, J. M. Girkin and M. D. Dawson, "Individually-addressable flip-chip AlInGaN micropixelated light emitting diode arrays with high continuous and nanosecond output power", Opt. Express, vol. 16, pp. 9918-9926, 2008

[9] J. J. D. McKendry, B. R. Rae, Z. Gong, K.R. Muir, B. Guilhabert, D. Massoubre, E. Gu, D. Renshaw, M. D. Dawson and R. K. Henderson, "Individually Addressable AlInGaN Micro-LED Arrays With CMOS Control and Subnanosecond Output Pulses", IEEE Photon. Technol. Let., vol. 21, pp. 811-813, 2009

[10] D. Elfstrom, B. Guilhabert, J. J. D. McKendry, S. Poland, Z. Gong, D. Massoubre, E. Richardson, B. R. Rae, G. Valentine, G. Blanco-Gomez, E. Gu, J. M. Cooper, R. K. Henderson and M. D. Dawson, "Mask-less ultraviolet photolithography based on CMOS-driven micro-pixel light emitting diodes", Opt. Express, vol. 17, pp. 23522-23529, 2009

[11] Z. J. Liu, K. M. Wong, C. W. Keung, C. W. Tang and K. M. Lau, "Monolithic LED microdisplay on active matrix substrate using flipchip technology", JSTQE, vol. 15, pp. 1298-1302, 2009

[12] B. R. Rae, C. Griffin, J. J. D. McKendry, J. M. Girkin, H. X. Zhang, E. Gu, D. Renshaw, E. Charbon, M. D. Dawson and R. K. Henderson," CMOS driven micro-pixel LEDs", J. Phys. D: Appl. Phys., vol. 41, pp. 094011, 2008

[13] A. Zarowna-Dabrowska, S. L. Neale, D. Massoubre, J. J. D. McKendry, B. R. Rae, R. K. Henderson, M. J. Rose, H. Yin, J. M. Cooper, E. Gu and M. D. Dawson, "Miniaturized optoelectronic tweezers controlled by GaN micro-pixel light emitting diode arrays", Opt. Express, vol. 19, pp. 2720-2728, 2011

[14] M. Wu, Z. Gong, D. Massoubre, Y. Zhang, E. Richardson, E. Gu and M. D. Dawson, "Ink-jet printed silver nanoparticles electrodes on GaNbased micro-structured light-emitting diodes", Appl. Phys. A., vol. 104, pp. 1003-1009, 2011

[15] R. J. Baker, "CMOS, circuit design, layout and simulation", $2^{\text {nd }}$ edition, Piscataway, NJ: IEEE Press, 2005, 72-73 